\title{
Erratum to: Standalone personal health records in the United States: meeting patient desires
}

\author{
Kevin T. Fuji • Amy A. Abbott • Kimberly A. Galt • \\ Andjela Drincic • Mark Kraft • Ted Kasha
}

Published online: 23 June 2012

(C) IUPESM and Springer-Verlag 2012

Erratum to: Health Technol.

DOI 10.1007/s12553-012-0028-1

Unfortunately, the acknowledgement of the funding source is missing in the published version of this article. The text is given below.

Acknowledgements This project was supported by grant number R24HS018625 from the Agency for Healthcare Research and Quality. The content is solely the responsibility of the authors and does not necessarily represent the official views of the Agency for Healthcare Research and Quality.

The online version of the original article can be found at http://dx.doi.org/ 10.1007/s12553-012-0028-1.

K. T. Fuji $(\bowtie) \cdot$ A. A. Abbott $\cdot$ K. A. Galt $\cdot$ M. Kraft $\cdot$ T. Kasha Creighton University Center for Health

Services Research and Patient Safety,

2500 California Plaza,

Omaha, NE 68178, USA

e-mail:kfuji@creighton.edu

A. Drincic

University of Nebraska Medical Center,

984120 Nebraska Medical Center,

Omaha, NE 68198, USA

A. A. Abbott

Creighton University School of Nursing,

2500 California Plaza,

Omaha, NE 68178, USA 